\title{
TESTING THE CHARACTERISTICS OF FREE AND FORCED OSCILLATIONS ON FAP 2228 OFF-ROAD VEHICLE
}

\author{
Aleksandar Mićović* \\ Technical Test Center, Belgrade, Serbia \\ Dr Vladimir Popović \\ Faculty of Mechanical Engineering, Belgrade, Serbia \\ Dragoslava Mićović \\ Academy of Criminalistic and Police Studies, Belgrade, Serbia \\ Snežana Jovanović \\ Technical Test Center, Belgrade, Serbia
}

The paper presents the testing of free and forced oscillations characteristics on FAP 2228 BS/A-45 off-road vehicle. The testing of free oscillations was conducted according to SORS 9127 (Standard of Defence of the Republic of Serbia) in laboratory conditions. The testing of forced oscillations was conducted in the course of driving on various surface paths - the heath in Deliblatska pescara, gravel at the territory of Fruska gora, on concrete surface at the runway of the Kovin airport, as well as on the asphalt surface of Belgrade-Šid highway. The testing was carried out according to SORS 0318 and ISO 2631 standards, and the results were evaluated according to 2002/44/EC Directive.

Key words: FAP 2228 BS/A-45, Forced oscillations, Free oscillations, Testing, Comfort

\section{INTRODUCTION}

The concept of military vehicles refers primarily to engine-driven special purpose off-road vehicles. It covers various military systems driven by internal combustion engines, such as tanks, infantry armoured fighting vehicles, as well as a number of other special superstructures on offroad vehicles. This is exactly the group of vehicles which are not covered by ecological standards in practice.

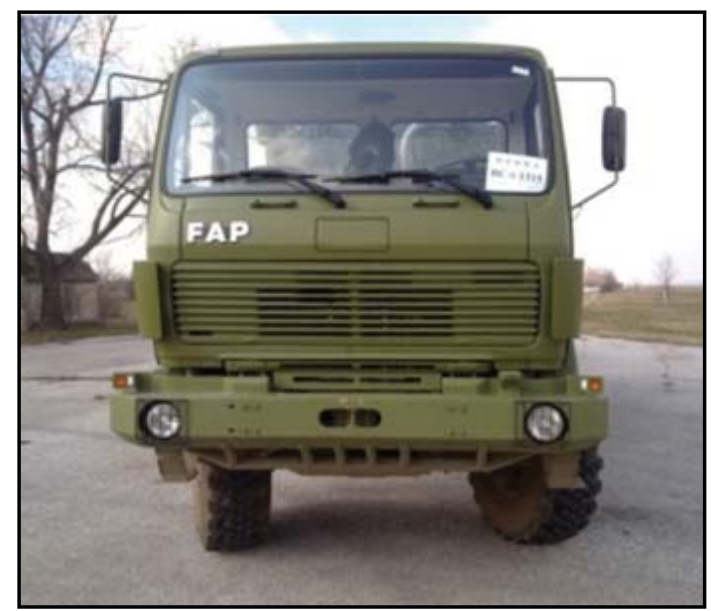

Figure 1: FAP 2228 BS/A-45
As these vehicles are not used only during war, but also in peace time, it is necessary to establish the standards which must be applied in order to protect the health of their users. A special problem related to military vehicles results from the fact that they are very durable and last long, and therefore they do not fulfil the standards which the automobile industry started applying in the last ten years $[05,07]$. Also, due to the special requirements set before the manufacturers regarding dynamic passability, the autonomous movement, the reliability of fitted components, as well as the accommodation of special equipment and weaponry, the price of manufacturing such vehicles is very high. It is a frequent case in practice that during the designing of superstructures to be installed on a basic type of a vehicle the constructors are faced with huge problems how to reduce the level of vibrations and noise inside the cabin to an acceptable level required for uninterrupted operation of the carrier $[06,08]$. The main and transversal supports are connected by screws and rivets. The platform is equipped with JOST locks for container connecting. Overall dimensions of the vehicle are (length $x$ width $\mathrm{x}$ height) $9,615 \times 2,500 \times 3,180 \mathrm{~mm}$.

* Technical Test Center, Vojvode Stepe 445, 11000 Belgrade, Serbia; amicovic1@gmail.com 


\section{FATIGUE AND VIBRATIONS}

Military vehicles are primarily used in off-road, or all terrain conditions. When they are tested, the test drivers from Technical Testing Centre usually cover several thousands of kilometres on various surfaces and in various weather conditions, putting them to test by intensive driving.

Most of these vehicles are in prototype stage of development where various functional failures are possible. This is why the concentration of a test driver is of great importance for the safety of testing. However, the necessary consequence of intensive driving testing is the fatigue which occurs in operators [01]. According to a definition, fatigue is a phenomenon occurring as a consequence of the activities of a human body as a whole or an organic system in overcoming various types of burden defined by work requirements. Fatigue warns a body to cease the activity due to overburden and possible consequences. The important characteristic of fatigue is reversibility.

When they are in drive, all types of vehicles can be a sources of vibrations which are transfered to the whole body of a driver. The risk of health damage increases in people who are exposed to high level of vibrations on a regular basis and over the long term. In order to determine a daily exposure to vibrations $(A(8))$ or VDV (Vibration Dose Value), it is necessary to know the duration of total daily exposure to vibrations produced by vehicles used during the work process. Only the data referring to the concrete work process should be taken into account at that, i.e. only the time period during which a driver or a crew member was exposed to vibrations.

Testing of the human exposure to vibrations which are transferred to the whole body is carried out according to the method defined in ISSO 2631-1:1997, while the detailed instructions on the application of the vibration measuring method are given in the European Standard EN 14253:2003. The level of vibrations expressed as r. m. s. value (root-meansquare) is expressed as acceleration weighted considering frequency measured at the seat of a person sitting in the course of performing their work tasks, i.e. the feet of the person who is standing during the performance of their work tasks, and it is given as $\mathrm{m} / \mathrm{s}^{2}$. The level of vibrations expressed as r. m. $\mathrm{s}$. value is equal to average acceleration measured in the interval of measurement conducted. This is the highest of the three values measured in three orthogonal axes (1.4 awx, 1.4 awy or awz) [09].
The alternative measure of the level of exposure to vibrations is Vibration Dose Value (VDV). VDV has been developed as a measure which represents a better risk indicator or exposure to vibrations with shocks. VDV is expressed in meter per second on 1.75th $(\mathrm{m} / \mathrm{s} 1.75)$ and as opposed to the level of vibrations expressed as r. m. s. value it represents a cumulative measuring result, i.e. it increases as the measuring time is prolonged. This is why it is important to know during all VDV measurements in which time period the value was measured. It should be the highest value measured in one of the three orthogonal axes (1,4 VDVwx, 1,4 VDVwy or VDVwz) [04].

Risk assessment must enable to recognize the method which can control the exposure to vibrations. When evaluating the exposure to vibrations, the work processes that cause them must also be taken into account. Understanding of the manner in which the workers are exposed to vibrations will help recognize the method for the reduction or complete elimination of this exposure $[02,03]$.

\section{VIBRATION (FREE AND FORCED) MEASURING}

Portable MAESTRO human vibration meter, manufactured by $01 \mathrm{~dB}-M e t r a v i b$, was used to measure the vibrations on the seats of both the driver and passengers in the vehicle cabin and the superstructure. This meter is intended primarily for human vibration measuring, i.e. measuring and calculating the influence on the human body (measurement of vibrations at the workplace which are transferred to the whole body or to the hands).

Alternatively, it is used to measure the level of noise (as four-channel system, the first three channels are intended for three-axis accelerometers, and the fourth channel can be connected to the oneaxis accelerometer or to a preamplifier with a microphone; it is adapted for measuring the efficiency of the seat and as a basic vibration meter).

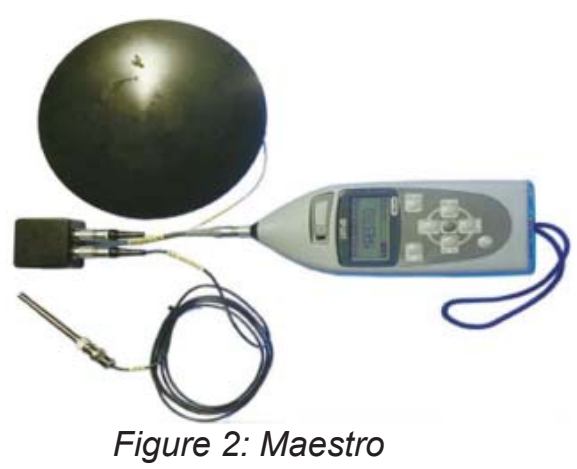

Journal of Applied Engineering Science 11(2013)4, 263 


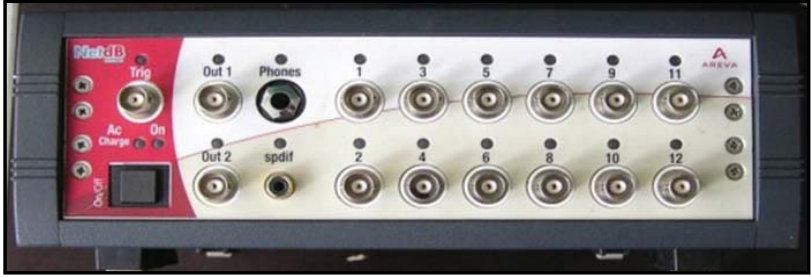

Figure 3: NetdB12

Its integration time ranges between 1 and 200 seconds and it has the possibility of start/stop mode, the memory capacity is $2 \mathrm{MB}$, as well as analogue output: 4-pin LEMO connector for signal recording or monitoring of all four channels within the range from 0.4 to $1000 \mathrm{~Hz}$. The autonomous operation (when not plugged in mode) depends on the battery life and on an average it is from 8 to 13 hours. Free oscillations were measured by NetdB12 (01dB Metravib) vibroacoustic measuring system manufactured by Areva, as well as NF piezoelectric accelerometers (type STS AS135/1A).

\section{FREE OSCILLATIONS MEASURING}

Testing of free oscillations was carried out in laboratory conditions on a flat concrete surface according to SORS 9127 . The vehicle is equipped with dependent elastic suspension system on the front bridge with leaf springs, additional rubber cushions and telescopic hydraulic shock absorbers (left and right).

Measurements were carried out on two points:

- $\mathrm{M}_{1}-$ vehicle frame above the middle of the axle, and

- $\mathrm{M}_{2}$ - vehicle frame above the centre of the tandem of vehicle back axles.

Exciting a vehicle to natural oscillation is performed by stretching, i.e. free fall of the vehicle ends: front end for measuring point $\mathrm{M}_{1}$ and rear end for $\mathrm{M}_{2}$. Out of the recorded signal as evaluating parameters for free oscillations fo natural frequency and relative coefficient of damping $\Psi$ are taken. As SORS 9127 refers to comfort characteristics - the evaluation of fo and $\Psi$ parameters is given according to the criteria for human organism. From the recorded oscillation signals the values of fo and $\Psi$ parameters were calculated in the form of damped sine wave and the results are shown in Table 1. On the front axle $\left(\mathrm{M}_{1}\right)$ the parameter of natural frequency suggests comfortable drive, while the coefficient of damping lies on the dividing line between comfortable and uncomfortable driving.

Table 1: Natural frequency $f_{o}$ and relative coefficient of damping $\psi$

\begin{tabular}{|c|c|c|c|c|}
\hline Vehicle & Measuring points & Parameters & Measured values & Comfort evaluation \\
\hline \multirow{4}{*}{ 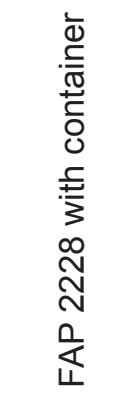 } & \multirow{2}{*}{$M_{1}$} & $f_{o}$ & $2,3 \mathrm{~Hz}$ & Comfortable \\
\hline & & $\psi$ & 0,35 & Conditionally comfortable \\
\hline & \multirow{2}{*}{$\mathrm{M}_{2}$} & $f_{o}$ & $3 \mathrm{~Hz}$ & Conditionally comfortable \\
\hline & & $\psi$ & 0,9 & Uncomfortable \\
\hline
\end{tabular}

On the measuring point at the centre of tandem axle $\left(M_{2}\right)$ the parameter of natural frequency is within the range of conditionally comfortable driving, and the coefficient of damping suggests extremely uncomfortable driving. Table 2 shows the results of measuring the total weight of the vehicle with the container, as well as the weight distribution on the sides and axles.

In addition to the surface on which the vehicle is being driven, one of the most important parameters that have significant influence on measuring results is also the speed of the vehicle.
This parameter has been chosen based on more than 20-year-long experience of the researchers of testing vehicles on testing paths in both Deliblatska pescara and Fruska gora. Realistic average speed on this type of surface is $30 \mathrm{~km} / \mathrm{h}$, but in order to obtain a more comprehensive insight into the measuring results and their comparison, the testing was also carried out at the speed of $40 \mathrm{~km} / \mathrm{h}$. Figures 4 through 6 show the examples of measuring results, while Table 3 shows the general results for all types of surfaces and all vehicle speeds. 
Table 2: Weight distribution on axles and sides

\begin{tabular}{|c|c|c|c|c|c|}
\hline & & & & $\begin{array}{l}\text { Vehicle without the } \\
\text { container [kg] }\end{array}$ & $\begin{array}{c}\text { Vehicle with the } \\
\text { container [kg] }\end{array}$ \\
\hline \multicolumn{4}{|c|}{ Total weight, $\mathbf{G}_{\mathrm{tw}}$} & 10900 & 16100 \\
\hline \multirow{12}{*}{ 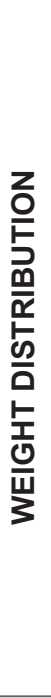 } & \multirow{3}{*}{\multicolumn{2}{|c|}{ Front axle }} & Left wheel, $\mathrm{G}_{\mathrm{fl}}$ & 2400 & 2380 \\
\hline & & & Right wheel, $\mathrm{G}_{\mathrm{fr}}$ & 2670 & 2620 \\
\hline & & & Total, $\mathrm{G}_{\mathrm{f}}$ & 5070 & 5000 \\
\hline & \multirow{7}{*}{ Tandem axle } & \multirow{3}{*}{ Middle axle } & Left wheel, $\mathrm{G}_{\mathrm{ml}}$ & 1550 & 2940 \\
\hline & & & Right wheel, $\mathrm{G}_{\mathrm{mr}}$ & 1540 & 2920 \\
\hline & & & Total, $\mathrm{G}_{\mathrm{m}}$ & 3090 & 5860 \\
\hline & & \multirow{3}{*}{ Rear axle } & Left wheel, $\mathrm{G}_{\mathrm{rl}}$ & 1360 & 2630 \\
\hline & & & Right wheel, $\mathrm{G}_{\mathrm{rr}}$ & 1380 & 2610 \\
\hline & & & Total, $\mathrm{G}_{\mathrm{r}}$ & 2740 & 5240 \\
\hline & & \multicolumn{2}{|c|}{ Total tandem weight, $\mathbf{G}_{\mathrm{T}}$} & 5830 & 11100 \\
\hline & \multicolumn{3}{|c|}{ Left side of the vehicle, $\mathrm{G}_{\mathrm{I}}$} & 5310 & 7950 \\
\hline & \multicolumn{3}{|c|}{ Right side of the vehicle, $G_{r}$} & 5590 & 8150 \\
\hline
\end{tabular}

Table 3: General review of forced oscillations measuring results

\begin{tabular}{|c|c|c|c|c|c|c|}
\hline Path & $\begin{array}{l}\text { Measuring } \\
\text { point }\end{array}$ & $\begin{array}{l}\text { Speed } \\
(\mathrm{km} / \mathrm{h})\end{array}$ & $\begin{array}{c}\text { Equivalent three- } \\
\text { axle acceleration } \\
\text { related to comfort } \\
\quad a_{v}\left(\mathrm{~m} / \mathrm{s}^{2}\right) \\
\end{array}$ & Comfort evaluation & $\begin{array}{l}\text { Equivalent three- } \\
\text { axle acceleration } \\
\text { related to health } \\
a_{v}\left(\mathrm{~m} / \mathrm{s}^{2}\right)\end{array}$ & $\begin{array}{l}\text { Recommended } \\
\text { maximum } \\
\text { exposure }\end{array}$ \\
\hline \multirow{9}{*}{ Asphalt } & \multirow{3}{*}{ Driver } & 50 & 0.78 & somewhat & 0.85 & $22 \mathrm{~h} 22 \mathrm{~m} 13 \mathrm{~s}$ \\
\hline & & 60 & 0.74 & somewhat & 0.81 & $23 \mathrm{~h} 54 \mathrm{~m} 28 \mathrm{~s}$ \\
\hline & & 70 & 0.73 & somewhat & 0.80 & $24 \mathrm{~h} 34 \mathrm{~m} 1 \mathrm{~s}$ \\
\hline & \multirow{3}{*}{ Codriver } & 50 & 1.06 & uncomfortable & 1.13 & $11 \mathrm{~h} 7 \mathrm{~m} 22 \mathrm{~s}$ \\
\hline & & 60 & 1.04 & uncomfortable & 1.11 & $11 \mathrm{~h} 29 \mathrm{~m} 44 \mathrm{~s}$ \\
\hline & & 70 & 0.98 & uncomfortable & 1.04 & $12 \mathrm{~h} 55 \mathrm{~m} 2 \mathrm{~s}$ \\
\hline & \multirow{3}{*}{ Crew } & 40 & 0.64 & somewhat & 0.67 & $28 \mathrm{~h} 14 \mathrm{~m} 37 \mathrm{~s}$ \\
\hline & & 50 & 0.80 & uncomfortable & 0.84 & $18 \mathrm{~h} 17 \mathrm{~m} 1 \mathrm{~s}$ \\
\hline & & 60 & 1.33 & very uncomfortable & 1.40 & $6 \mathrm{~h} 43 \mathrm{~m} 18 \mathrm{~s}$ \\
\hline \multirow{4}{*}{ Concrete } & \multirow{2}{*}{ Driver } & 60 & 0.88 & uncomfortable & 0.97 & $17 \mathrm{~h} 36 \mathrm{~m} 50 \mathrm{~s}$ \\
\hline & & 80 & 0.99 & uncomfortable & 1.08 & $13 \mathrm{~h} 28 \mathrm{~m} 10 \mathrm{~s}$ \\
\hline & \multirow{2}{*}{ Codriver } & 50 & 1.11 & uncomfortable & 1.19 & $10 \mathrm{~h} 10 \mathrm{~m} 39 \mathrm{~s}$ \\
\hline & & 70 & 1.05 & uncomfortable & 1.16 & $12 \mathrm{~h} 42 \mathrm{~m} 1 \mathrm{~s}$ \\
\hline \multirow{4}{*}{ Heath } & \multirow{2}{*}{ Driver } & 30 & 1.18 & uncomfortable & 1.36 & $11 \mathrm{~h} 38 \mathrm{~m} 31 \mathrm{~s}$ \\
\hline & & 40 & 1.64 & very uncomfortable & 1.87 & $5 \mathrm{~h} 38 \mathrm{~m} 41 \mathrm{~s}$ \\
\hline & \multirow{2}{*}{ Codriver } & 30 & 1.36 & very uncomfortable & 1.50 & $7 \mathrm{~h} 26 \mathrm{~m} 32 \mathrm{~s}$ \\
\hline & & 40 & 1.57 & very uncomfortable & 1.73 & $5 \mathrm{~h} 30 \mathrm{~m} 06 \mathrm{~s}$ \\
\hline \multirow{8}{*}{ Gravel } & \multirow{3}{*}{ Driver } & 20 & 1.06 & uncomfortable & 1.12 & $10 \mathrm{~h} 22 \mathrm{~m} 39 \mathrm{~s}$ \\
\hline & & 30 & 1.46 & very uncomfortable & 1.63 & $6 \mathrm{~h} 42 \mathrm{~m} 55 \mathrm{~s}$ \\
\hline & & 40 & 1.17 & uncomfortable & 1.32 & $10 \mathrm{~h} 55 \mathrm{~m} 4 \mathrm{~s}$ \\
\hline & \multirow{3}{*}{ Codriver } & 20 & 1.40 & very uncomfortable & 1.50 & $6 \mathrm{~h} 25 \mathrm{~m} 16 \mathrm{~s}$ \\
\hline & & 30 & 1.37 & very uncomfortable & 1.48 & $6 \mathrm{~h} 50 \mathrm{~m} 31 \mathrm{~s}$ \\
\hline & & 40 & 1.64 & very uncomfortable & 1.77 & $4 \mathrm{~h} 43 \mathrm{~m} 41 \mathrm{~s}$ \\
\hline & \multirow{2}{*}{ Crew } & 30 & 0.99 & uncomfortable & 1.07 & $12 \mathrm{~h} 43 \mathrm{~m} 28 \mathrm{~s}$ \\
\hline & & 40 & 1.43 & very uncomfortable & 1.51 & $5 \mathrm{~h} 46 \mathrm{~m} 11 \mathrm{~s}$ \\
\hline
\end{tabular}




\begin{tabular}{|c|c|c|c|c|c|c|}
\hline File & \multicolumn{6}{|c|}{ Vozac 40km MM1.cmg } \\
\hline \multicolumn{7}{|l|}{ Location } \\
\hline Start & \multicolumn{6}{|c|}{ 05-03-13 11:11:47 } \\
\hline End & \multicolumn{6}{|c|}{ 05-03-13 11:13:25 } \\
\hline \multicolumn{7}{|c|}{ Whole body } \\
\hline Quality & \multicolumn{6}{|c|}{ Health } \\
\hline Body position & \multicolumn{6}{|l|}{ Seated } \\
\hline Measurement location & \multicolumn{6}{|l|}{ Seat } \\
\hline \multicolumn{7}{|l|}{ Type } \\
\hline Axis & $\mathrm{x}$ & $\mathrm{Y}$ & $z$ & \multirow{4}{*}{$\begin{array}{c}\text { Overal } \\
\text { av }\end{array}$} & \multirow{4}{*}{$\begin{array}{c}\text { Overall } \\
A(8)\end{array}$} & \multirow[t]{4}{*}{ Exposure } \\
\hline Weighting & Wd & Wd & Wh & & & \\
\hline Coefficient & 1.4 & 1.4 & 1 & & & \\
\hline Level (m/s2) & 0.65 & 0.63 & 1.37 & & & \\
\hline Corrected (m/s2) & 0.91 & 0.89 & 1.37 & 1.8 & 1.37 & $8 \mathrm{n}$ \\
\hline Warning level (m/s2) & & & & & 0.50 & $1 \mathrm{~h} 4 \mathrm{~m} 1 \mathrm{~s}$ \\
\hline Maximum level (m/s2) & & & & & 1.15 & $5 \mathrm{~h} 38 \mathrm{~m} 41 \mathrm{~s}$ \\
\hline eVDV dose (m/s 1.75) & 16.57 & 16.21 & 24.97 & & & $8 \mathrm{~h}$ \\
\hline \multicolumn{7}{|c|}{ Exposure level $A(8)$ is above maximum level } \\
\hline Type & \multicolumn{6}{|c|}{ Peakfactor } \\
\hline Axis & \multicolumn{2}{|l|}{$\mathrm{x}$} & \multicolumn{2}{|c|}{\begin{tabular}{l|l}
$Y$ & \\
&
\end{tabular}} & \multirow{2}{*}{$\begin{array}{c}\mathrm{Z} \\
3.68\end{array}$} & Max. \\
\hline Peakfactor & 3.48 & & 3.15 & & & 3.68 \\
\hline \multicolumn{7}{|c|}{ Peak factor is smaller than 9} \\
\hline \multicolumn{7}{|c|}{ According to Standard 2631-1, $A(8)$ assessment is recommended } \\
\hline Type & \multicolumn{6}{|c|}{ VDV } \\
\hline Axis & $x$ & $\mathrm{Y}$ & & \begin{tabular}{|l|}
$z$ \\
\end{tabular} & \multirow{4}{*}{$\begin{array}{l}\text { Max. } \\
\text { VDVeq }\end{array}$} & \multirow[t]{4}{*}{ Exposure } \\
\hline Weighting & Wd & Wo & & Wh & & \\
\hline Coefficient & 1.4 & 1.4 & & 1 & & \\
\hline VDV dose (m/s 1.75) & 2.81 & 2.6 & & .40 & & \\
\hline Corrected (m/s 1.75) & 3.94 & 3.7 & & .40 & 6.40 & $1 \mathrm{~m} 38 \mathrm{~s}$ \\
\hline Warning level (m/s 1.75) & & & & & 9.10 & \\
\hline Maximum level (m/s 1.75) & & & & & 21.00 & \\
\hline
\end{tabular}

\begin{tabular}{|c|c|c|c|c|}
\hline File & \multicolumn{4}{|c|}{ Vozac $40 \mathrm{~km}$ MM1.cmg } \\
\hline \multicolumn{5}{|l|}{ Location } \\
\hline Start & \multicolumn{4}{|c|}{ 05-03-13 11:11:47 } \\
\hline End & \multicolumn{4}{|c|}{ 05-03-13 11:13:25 } \\
\hline \multicolumn{5}{|c|}{ Whole body } \\
\hline Quality & \multicolumn{4}{|c|}{ Comfort } \\
\hline Body position & \multicolumn{4}{|c|}{ Seated } \\
\hline Measurement location & \multicolumn{4}{|c|}{ Seat } \\
\hline Type & \multicolumn{4}{|c|}{ aw } \\
\hline Axis & $x$ & $\mathrm{Y}$ & $Z$ & Overall \\
\hline Weighting & Wd & Wd & Wh & av \\
\hline Level (mis2) & 0.65 & 0.63 & 1.37 & 1.64 \\
\hline
\end{tabular}

Figure 4: Driver's seat, speed $40 \mathrm{~km} / \mathrm{h}$, heath

\section{CONCLUSION}

In order to obtain more comprehensive results on asphalt and concrete surfaces respectively, the measurements were carried out at constant speeds ranging from 40 to $80 \mathrm{~km} / \mathrm{h}$. Tests were made on the Kovin airport runway and on the part of highway near Sremska Mitrovica. Re-

\begin{tabular}{|c|c|c|c|c|c|c|}
\hline File & \multirow{2}{*}{\multicolumn{6}{|c|}{ Vozac 80 Asfalt pista Kovin.cmg }} \\
\hline Location & & & & & & \\
\hline Start & \multicolumn{6}{|c|}{$14-11-1216: 30: 43$} \\
\hline End & \multicolumn{6}{|c|}{ 14-11-1216:32:05 } \\
\hline \multicolumn{7}{|c|}{ Whole body } \\
\hline Quality & \multicolumn{6}{|c|}{ Health } \\
\hline Body position & \multirow{2}{*}{\multicolumn{6}{|c|}{$\begin{array}{l}\text { Seated } \\
\text { Seat }\end{array}$}} \\
\hline Measurement location & & & & & & \\
\hline \multicolumn{7}{|l|}{ 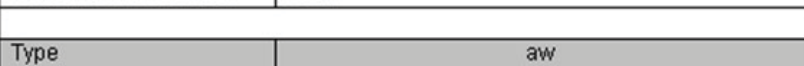 } \\
\hline Axis & $\mathrm{x}$ & $\mathrm{Y}$ & $z$ & \multirow{4}{*}{$\begin{array}{c}\text { Overall } \\
\text { av }\end{array}$} & \multirow{4}{*}{$\begin{array}{c}\text { Overall } \\
A(8)\end{array}$} & \multirow[t]{4}{*}{ Exposure } \\
\hline Weighting & Wd & Wd & Wk & & & \\
\hline Coefficient & 1.4 & 1.4 & 1 & & & \\
\hline Level (m/s2) & 0.34 & 0.28 & 0.89 & & & \\
\hline Corrected (mis2) & 0.48 & \multirow[t]{3}{*}{0.39} & 0.89 & \multirow[t]{3}{*}{1.08} & 0.89 & $8 \mathrm{~h}$ \\
\hline Warning level (m/s2) & & & & & 0.50 & $2 \mathrm{~h} 32 \mathrm{~m} 46 \mathrm{~s}$ \\
\hline Maximum level (m/s2) & & & & & 1.15 & $13 \mathrm{~h} 28 \mathrm{~m} 10 \mathrm{~s}$ \\
\hline \multicolumn{7}{|c|}{ Exposure level $A(8)$ is above warning level } \\
\hline Type & \multicolumn{6}{|c|}{ Peak factor } \\
\hline Axis & \multirow{2}{*}{\multicolumn{2}{|c|}{$\frac{X}{3.18}$}} & \multirow{2}{*}{\multicolumn{2}{|c|}{$\frac{Y}{3.18}$}} & $z$ & Max. \\
\hline Peakfactor & & & & & 3.83 & 3.83 \\
\hline \multicolumn{7}{|c|}{ Peak factor is smaller than 9} \\
\hline \multicolumn{7}{|c|}{ According to Standard $2631-1, A(8)$ assessment is recommended } \\
\hline Type & \multicolumn{6}{|c|}{ VDV } \\
\hline Axis & $\mathrm{x}$ & & $\bar{Y}$ & \begin{tabular}{l|l}
$z$ &
\end{tabular} & \multirow{4}{*}{$\begin{array}{c}\text { Max. } \\
\text { voveq }\end{array}$} & \multirow[t]{4}{*}{ Exposure } \\
\hline Weighting & Wd & & Vd & Wk & & \\
\hline Coefficient & 1.4 & & .4 & 1 & & \\
\hline VDV dose (m/s 1.75) & 1.38 & 1. & 13 & 4.32 & & \\
\hline Corrected (m/s 1.75) & 1.94 & 1. & 58 & 4.32 & 4.32 & $1 \mathrm{~m} 22 \mathrm{~s}$ \\
\hline Warning level (m/s 1.75) & & & & & 9.10 & \\
\hline Maximum level (mis 1.75) & & & & & 21.00 & \\
\hline
\end{tabular}

\begin{tabular}{|c|c|c|c|c|}
\hline File & \multicolumn{4}{|c|}{ Vozac 80 Asfalt pista Kovin.cmg } \\
\hline \multicolumn{5}{|l|}{ Location } \\
\hline Start & \multicolumn{4}{|c|}{$14-11-1216: 30: 43$} \\
\hline End & \multicolumn{4}{|c|}{$14-11-1216: 32: 05$} \\
\hline \multicolumn{5}{|c|}{ Whole body } \\
\hline Quality & \multicolumn{4}{|c|}{ Comfort } \\
\hline Body position & \multicolumn{4}{|c|}{ Seated } \\
\hline Measurement location & \multicolumn{4}{|c|}{ Seat } \\
\hline Type & \multicolumn{4}{|c|}{ aw } \\
\hline Axis & $x$ & $\bar{Y}$ & Z & Overall \\
\hline Weighting & Wd & Wd & Wk & av \\
\hline Level (mis2) & 0.34 & 0.28 & 0.89 & 0.99 \\
\hline
\end{tabular}

Figure 5: Driver's seat, speed $80 \mathrm{~km} / \mathrm{h}$, asphalt

gardless of a relatively wide speed interval, the results obtained of the equivalent levels of vibrations at the driver's seat range from 0.9 to $1 \mathrm{~m} / \mathrm{s} 2$ for the concrete surface and about $0.75 \mathrm{~m} / \mathrm{s} 2$ for asphalt surface; it can, therefore, be concluded that various speeds on either concrete or asphalt surface do not have any significant influence on the level of vibrations on either driver's or co-driver's seat. It can be noticed that at the same speed the vibrations at the co-driver's seat are about $10 \%$ higher on a concrete surface, but also about $30 \%$ on the asphalt surface. 


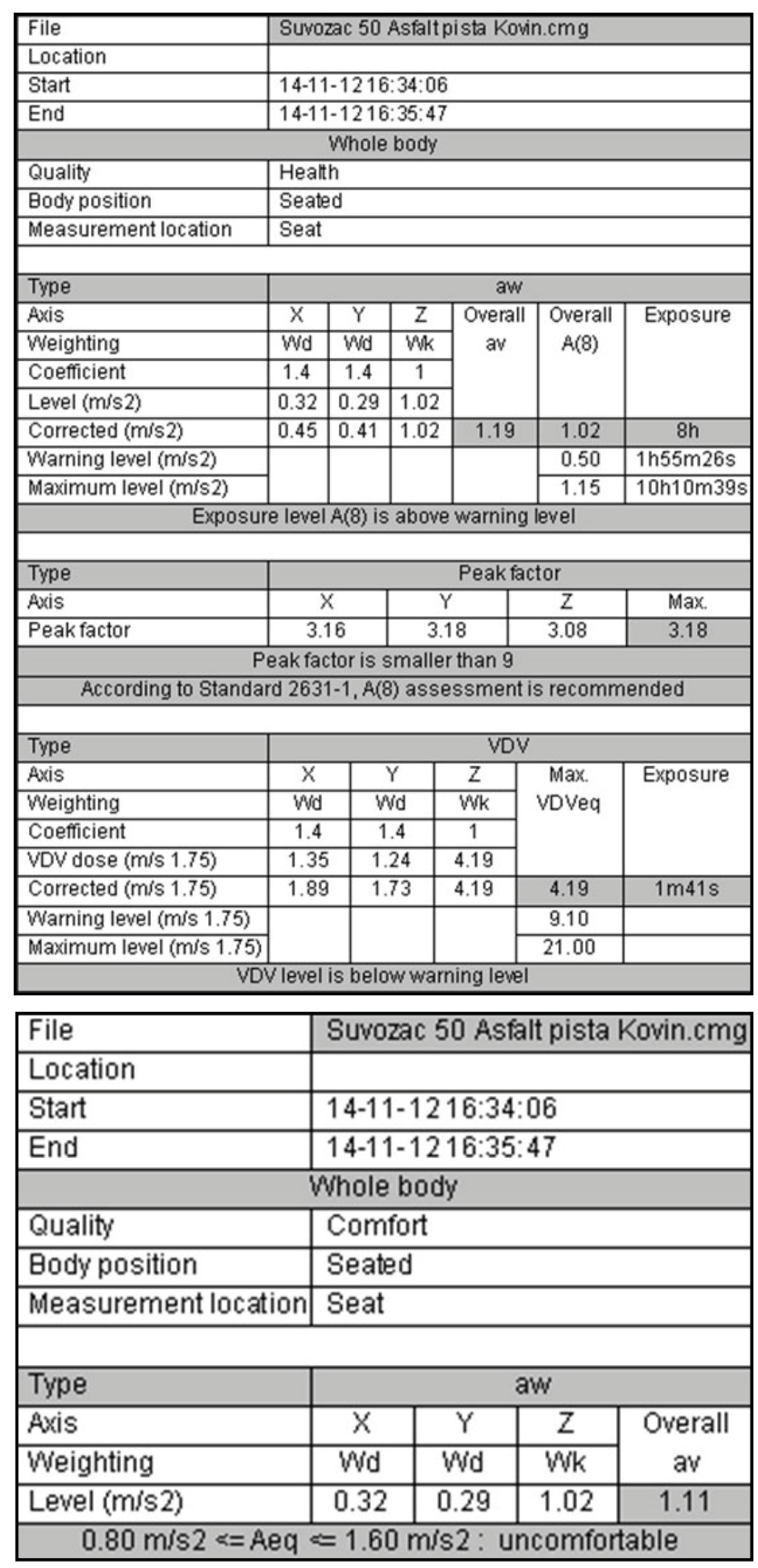

Figure 6. Co-driver's seat, speed $50 \mathrm{~km} / \mathrm{h}$, asphalt

Considering that both seats (the driver's and codriver's) are equipped with the same type of seats, it can be concluded that the distribution of burder, as well as the choice of vehicle suspension system have influence on this irregularity. The oscillations measured during driving on the asphalt surface at the driver's and co-driver's seat suggest uncomfortable drive, particularly at the speed of $50 \mathrm{~km} / \mathrm{h}$. Measuring of forced oscillations in the field following the comfort ability criteria suggests that driving at both the driver's and co-driver's seats can be classified as very uncomfortable on the macadam. This conclusion is also valid for the drive at the speed of $40 \mathrm{~km} / \mathrm{h}$ on the heath. In general, the results for the co-driver's seat are more unfavorable. In regard to the criteria of harm to health, the driving in this off-road vehicle on both the heath and macadam surfaces should be limited in time until the stated warning levels of vibrations.

\section{REFERENCES}

1) Bester, R.: The ride comfort versus handling decision for off-road vehicles, PhD thesis, Faculty of Engineering, Built environment and Information Technology (EBIT), University of Pretoria, Pretoria, 2006

2) Blagojević I., Ivanović G., Janković S., Popović V. (2012): A model for gear shifting optimization in motor vehicles, Transactions of FAMENA, 36 2, pp.51-66

3) Directive 2002/44/EC of the European Parliament and of the Council on the minimum health and safety requirements regarding the exposure of workers to the risks arising from physical agents (vibration), June 2002

4) ISO 2631 Mechanical vibration and shock - Evaluation of human exposure to wholebody vibration, 1997

5) Mikulić, D., Happ Z., Knezović M. (2004): Ecologically military vehicles, Hrvatski vojnik, No 109/110, pp 8-11

6) Mićović, A., Popović, A., Jovanović, S. (2012): Acoustic testing inside cabin and passenger space of off-road vehicle land rover defender 110 soft top, Proceeding of Papers 23th National conference \& 4th International conference - Noise and vibration, pp. 233 -235.

7) Popović V., Vasić B., Rakićević B., Vorotović G. (2012): Optimization of maintenance concept choice using risk-decision factor - a case study, International Journal of Systems Science,4310, pp.1913-1926

8) Stamenković D., Popović V., SpasojevićBrkić V., Radivojević J. (2011): Combination free replacement and pro-rata warranty policy optimization model, Journal of Applied Engineering Science, 9 ,pp. 457-464

9) Smith S, (2008): Dynamic characteristics and human perception of vibration aboard a military propeller aircraft Air Force Research Laboratory, AFRL/RHPA, International Journal of Industrial Ergonomics 38, pp 868-879

Paper sent to revision: 27.11.2013.

Paper ready for publication: 12.12.2013. 